\title{
The development and validation of the Rewards Desirability Inventory
}

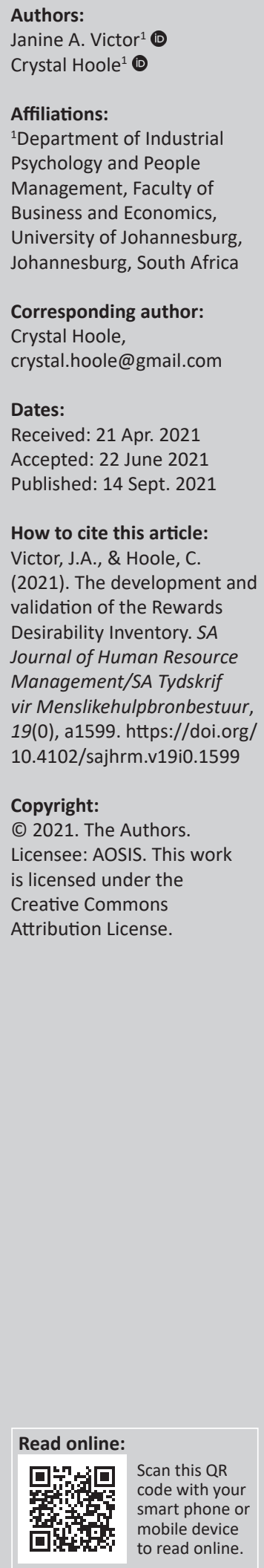

Orientation: Research on reward preferences remains inconclusive. Total reward theories often do not take the role of intrinsic psychological rewards into consideration. Further to this, there are not only limited instruments available to measure reward preferences but also ease of access to psychometrically sound measures is further challenging.

Research purpose: The aim of this study was to develop and validate an instrument to measure reward preferences in the working environment.

Motivation for the study: Organisations require tools to enhance waning motivational levels in the workplace. The measurement of reward preferences appears essential to determine what employees ultimately want from their work to improve levels of motivation. Major limitations exist regarding current reward preference instruments.

Research approach/design and method: Quantitative scale development procedures were employed to construct the 32-item instrument. Data were collected from South African employees $(N=639)$ and processed using both Factor and Rasch analysis procedures.

Main findings: The factor analysis revealed a 3-factor structure (Non-financial rewards, Financial rewards and Benefits and growth opportunities). Items evidenced good factor loadings and dimensions demonstrated high internal consistency. The dimensions and overall scale performed mostly well in accordance with Rasch Model expectations. Based on the overall results, one can confirm that the new instrument has satisfactory psychometric properties.

Practical/managerial implications: The instrument can help employers and scholars to measure, understand and explore what employees value and seek from the working environment.

Contribution/value-addition: The study expands on limited pre-existing theory and empirical research pertaining to the measurement of rewards preferences. A unique and psychometrically sound reward preference instrument is provided for use by scholars and employers.

Keywords: Reward preferences; factor analysis; Rasch Model; scale development; reliability; validation; South Africa; Rewards Desirability Inventory.

\section{Introduction \\ Orientation}

Organisations seek to know what motivates employees' and what they ultimately value from the employment relationship. Total rewards - financial and non-financial rewards that organisations offer to workers - motivate and drive employees to put forth their best efforts (Riaz, Akhtar, \& Aslam, 2018; WorldatWork, 2007). When worker productivity increases, so does company bottom line (Sels et al., 2006). The total reward concept is based on the belief that employees seek more than just money from the work that they do. It is important to note the individuality of each employee and how different rewards will affect them (Alhmoud \& Rjoub, 2019). Therefore, total rewards are strategic tools used by organisations to offer rewards which address individual employee values and needs (Bussin \& Van Rooy, 2014), thereby stimulating employee motivation (García, Ramón, \& Herrera, 2019).

Despite the influx of total reward research, there are still pitfalls in the total rewards domain. Brown (2014) advocated that total reward strategies are increasingly becoming outdated. Employees may be searching for more from their jobs, signifying that organisations are no longer able to satiate the motivational needs of their staff with current total reward models.

An overlooked way of rewarding employees is by focussing on the psychological façade of designing work to be more intrinsically motivating and satisfying (Renard \& Snelgar, 2016). Total 
rewards strategies place minimal, if any, emphasis on this approach. Work is not always a means to an end. Some people are strongly connected to what they do. It shapes their identities (Neves et al., 2018) and gives rise to inner fulfilment (Overell, 2009). The importance of the intrinsic psychological facet of rewards is that not only employees are rethinking the meaning of work, but are diverting from jobs based on salary and moving towards places of work which promote happiness and the opportunity to feel good (Achor, Reece, Kellerman, \& Robichaux, 2018). As advocated by Peng (2018), people are starting to reflect on the value of their work and take steps to acquire meaning by engaging in their actual work content. Evidently, employees are increasingly channelling their desires towards a more intrinsically rewarding workplace.

To measure preferences towards rewards and achieve the goals of this study, human resource practitioners as well as scholars require readily available instruments. Despite growing interest in reward preferences locally (e.g. Bussin \& Thabethe, 2018; Fobian \& Maloa, 2020; Nienaber, Bussin, \& Henn, 2011; Snelgar, Renard, \& Venter, 2013) and internationally (e.g. Acheampong, 2021; Adinew, 2020; French \& Emerson, 2014), there are not only limited instruments available to measure such preferences, but also ease of access to psychometrically sound measures is further challenging (Hoole \& Hotz, 2016; Victor \& Hoole, 2017). What is more, and to the researcher's knowledge, there are no holistic reward preference instruments available which account for measuring not only financial and non-financial rewards but also those intrinsic and psychological in nature.

\section{Research purpose and objectives}

The aforementioned highlights that there is a need to develop a psychometrically sound measuring instrument to explore reward preferences. To this end, the primary objective of this study was to develop and validate a rewards preference measure based on financial, non-financial and intrinsic psychological rewards. The motive for the development of this instrument is that thereare no currentand psychometrically sound scales readily available to measure such preferences.

\section{Literature review}

Reward is conceptualised as returns employees receive for carrying out tasks and responsibilities in the workplace (Jiang, Xiao, Qi, \& Xiao, 2009). There are various taxonomies, systems and frameworks for classifying rewards (Bussin, MohamedPadayachee, \& Serumaga-Zake, 2019). A popular basis for this is by distinguishing between different types of rewards such as intrinsic, extrinsic, direct, indirect, financial and nonfinancial rewards. These elements are increasingly being used by enterprises to design individualised and bespoke reward packages which align to employee preferences, desires and needs (Pregnolato, Bussin, \& Schlechter, 2017).

\section{Total rewards}

Rewards are important as they play an integral role in the field of talent management. Adequately designed reward systems are highly effective tools in enhancing employee motivation and boosting job satisfaction (Noor \& Zainordin, 2018). Several researchers have explored the total rewards concept (e.g. Bussin et al., 2019; Hoole \& Hotz, 2016; Pregnolato et al., 2017). Total rewards consist of different types of rewards which organisations offer to employees (Bussin et al., 2019; WorldatWork, 2010). Particularly, total rewards encapsulate all financial and non-financial returns which enterprises exert control over. Organisations frequently draw on different types of rewards to attract, motivate and retain talent (Armstrong, 2010). The modern development of rewards strategies focusses on ways in which organisations can enhance talent management practices, by drawing on both financial or transactional (such as pay and benefits in accordance with the employee-employer exchange) and non-financial or relational or intangible (such as learning and development opportunities as well as the working environment) returns (Bussin \& Van Rooy, 2014).

\section{Financial rewards}

Financial rewards are economic and monetary in nature. They are controlled directly by an organisation (Kshirsagar \& Waghale, 2014). Financial rewards are transactional and include pay and benefits (Armstrong, 2010). Whilst pay is attributable to direct means of compensation, benefits are more indirect in nature (Armstrong, 2010). Pay includes base pay and contingent or variable pay. Base pay includes, for example, one's remuneration or salary for actual work carried out on a monthly, hourly or weekly basis (Snelgar et al., 2013). Contingent or variable pay is not fixed and is dependent on variables such as performance, tenure and/or skillset (Horváthová, Davidová, \& Bendová, 2012). Rewards provided indirectly by an organisation include employee benefits (Armstrong, 2010). They are frequently used to supplement pay and protect employees from financial burdens (WorldatWork, 2010). They are considered discretionary in nature (Koskey \& Sakataka, 2015). Armstrong (2010) suggested that benefits include: (1) health-related benefits, (2) paid or personal time off and (3) retirement and pension benefits.

\section{Non-financial rewards}

Non-financial rewards consist of non-monetary returns. These rewards are deemed intangible (Joshi, 2016). Examples include learning and development opportunities and the working environment (Koskey \& Sakataka, 2015). Learning and development opportunities can be defined as opportunities provided to employees to develop their skillsets and enhance their knowledge within an organisation (Armstrong, 2010). Training, on-the-job or experiential learning, performance management, career development and succession planning encompass examples of learning and development opportunities (Armstrong, 2010). A working environment denotes the actual setting that employees work in (Ushie, Agba, \& Okorie, 2015). The working environment consists of the organisational culture, leadership, communication, involvement, work-life balance 
and non-financial recognition. Perry and Porter (1982) further advocated that the working environment includes having good relationships with colleagues and supervisors.

\section{Intrinsic psychological rewards}

Intrinsic rewards are those positive feelings (such as happiness) which derive from the working context (Obicci, 2015). They are intangible and psychological in nature (Jacobs, Renard, \& Snelgar, 2014). Such rewards derive from the actual job and work content (Renard \& Snelgar, 2016). These rewards include meaningful work, felt responsibility for work outcomes and autonomy, felt challenge, a sense of competence and task interest and enjoyment.

Meaningful work can be defined as one's experience and personal significance of work (Michaelson, 2019). As per the job characteristics model (Hackman \& Oldham, 1976), when certain job characteristics such as task identity and task significance are present, a psychological response is triggered whereby employees experience meaningfulness in their work. Whilst task identity is defined as the completion of a task from beginning until end with an identifiable outcome, task significance refers to the degree to which a job impacts on the lives of others (Hackman \& Oldham, 1976). When such psychological states are triggered, certain outcomes such as job satisfaction and work motivation are enhanced.

Felt responsibility can be defined as situations in which one feels obliged to perform, take action or deliver on something (Avey, Avolio, Crossley, \& Luthans, 2009). The job characteristics model (Hackman \& Oldham, 1976) particularly supports the inclusion of felt responsibility as an intrinsic psychological and motivational reward (Renard \& Snelgar, 2016) by advocating that experiencing responsibility for work outcomes serves as a critical psychological state which emanates from autonomy (Hackman \& Oldham, 1976). Autonomy, according to Hackman and Oldham (1976), is the degree to which a job provides an employee with adequate freedom and independence in carrying out, scheduling and determining procedures in work. Nguyen, Taylor and Bradley (2003) articulated that job autonomy may heighten enjoyment with work as employees are granted the opportunity to determine how to execute tasks to their liking. Pink (2009) advocated that autonomy is a pillar of motivation. In his theory, he described autonomy as the desire to direct our own behaviours, which leads positive attitudes and improved performance. Autonomous work, therefore, provides one with a sense of self-direction and choice, and which leads to heightened feelings of responsibility for workrelated outcomes (Ali et al., 2014).

Challenging work encapsulates tasks which are difficult yet energising (Preenen, Van Vianen, \& De Pater, 2014). As indicated in the two-factor theory, Herzberg et al. (1959) advocated that challenging work is regarded as a 'motivator'. Therefore, when people feel challenged in their work, they feel more motivated and report higher levels of satisfaction in their job. In particular, Herzberg's two-factor theory is based on the premise that there are two divisions of motivation: motivating factors (satisfiers) and hygiene factors (dissatisfiers). Motivating factors lead to job satisfaction. These factors encompass achievement, recognition, work itself, responsibility, advancement and growth (Ozsoy, 2019). Hygiene factors lead to job dissatisfaction (Herzberg, 1966). Such factors include, for example, working conditions, pay, relationships with colleagues, admin policies, company policies, supervision, relationships with supervisors, status and security (Ozsoy, 2019).

A sense of competence is conceptualised as the positive feelings that one gets when they are able to cope with tasks, exceed expectations and produce matter-worthy work. Basic psychological need satisfaction in self-determination theory (Ryan \& Deci, 2000) posits that satisfying the need for competence is a psychological and cognitive mechanism for enhancing one's motivation as well as satisfaction within a particular environment. According to Ryan and Deci (2000), not only does motivation drive certain behaviours but allows individuals to acquire a sense of fulfilment, which is associated with an internally rewarding experience. Specifically, motivation is enhanced when individuals are able to master difficult and challenging tasks. In this way, individuals feel more competent.

Task interest and enjoyment occur when employees find their work tasks fun or enjoyable to engage with (Crane, 2012). As a basis for self-determination theory, Ryan and Deci (2000) asserted that individuals are more inclined to persist with, gravitate towards and be motivated by tasks or activities that they find interesting or enjoyable (Williams, Niemiec, Patrick, Ryan, \& Deci, 2009). Rigby and Ryan (2018) argued that motivation may be energised by an employees' values, needs and interests. When volitional motivation occurs, employees demonstrate work commitment and attain improved levels of satisfaction, energy and wellness. Tasks which are both interesting and enjoyable, therefore, provide employees with a positive organisational experience.

\section{Reward preferences}

Preferences have been defined as an individual's liking, desire or favouring towards phenomenon (Scherer, 2005). Not only do preferences enhance an individual's sense of choice, but also when satisfied, they elicit positive feelings and emotions (Dolan \& Metcalfe, 2012). Although no universally agreed-upon definition has been formulated, reward preferences can be demarcated as the perceived desirability of work-related returns.

Reward preferences are significant in talent attraction and retention (Victor \& Hoole, 2017). An important proposition in literature is that rewards are embedded in motivational theory. The degree of motivation emanates from the extent to which rewards received are perceived as desirable (Chiang \& Birtch, 2005). This advocates that employee behaviour and motivation to perform in a job may be influenced by the extent to which rewards provided to them are appreciated. 


\section{Measuring reward preferences}

The Reward Preference Questionnaire (RPQ; Nienaber et al., 2011) is the most frequently used South African rewards preference measure. The construction of the RPQ was informed by a theoretical approach based on WorldatWork's total rewards framework (WorldatWork, 2007). Nienaber et al. (2011) identified categories used to classify reward components. They classified rewards as either total package (financial or extrinsic rewards) or additional rewards (nonfinancial or intrinsic rewards). Total package rewards comprised (1) family care, (2) medical aid and retirement funds and (3) reward performance, whilst additional rewards consisted of (4) performance and career management, (5) quality work environment, (6) empowerment, (7) flexible work practices, (8) control over my pay, (9) work relationships and teamwork and (10) development opportunities. Nienaber et al. (2011), Close and Martins (2015) and Hoole and Hotz (2016) have however, reported several discrepancies with the psychometric properties of the instrument, ranging from low reliability coefficients for various subscales to inconsistencies in the factor structure to complex wording of certain items. Snelgar et al. (2013) developed a modified version of the RPQ by modifying item wording and reducing the response categories to a 5-point scale. The subscales pertaining to the importance of rewards did, however, evidence low to good reliability coefficients, ranging from 0.52 to 0.82 . Unfortunately, there are very limited studies which have further scrutinised the psychometric properties of the modified version. Another instrument which has undergone modification and validation in the South African context is the SARM10 (Bussin, Nicholls, \& Nienaber, 2016). The SARM10 consists of 11 subscales namely, guaranteed package, short-term incentives, pension, job-level-based benefits, family-related benefits, job security, work hours, career and development, performance and recognition, team pay and team equal. Although the scale has undergone rigorous measurement model analysis by the developers, it has not been tested and validated by other researchers.

In light of the above, the intrinsic psychological façade of rewards remains precluded from these instruments. Moreover, despite limited attempts to develop, refine and validate these reward preferences measures, many reward surveys administered to employees are not based on empirical research (Nicholls, 2012). Given this, there is a lack of suitable reward preferences instruments in the South African context. The lack of testing and inconsistent psychometric properties reported in literature as well as the exclusion of an intrinsic psychological component in the questionnaires, serves as the underpinning motive for the development of a more intricate reward preference instrument.

\section{Research design \\ Research approach}

To develop the reward preferences instrument, an exploratory sequential research design was employed. This article constitutes the second phase and was established on findings from the initial qualitative phase. The qualitative phase was used to define the construct, ensure content and face validity and inform the items. During the first phase, data were collected using focus group discussions and analysed using a deductive and constructionist thematic analysis. Findings revealed that the total compensation package encapsulated financial rewards. Underlying non-financial rewards were good relationships, learning and development opportunities, organisational culture, communication, recognition, physical working environment, feedback and work-life balance. Underlying intrinsic psychological rewards were autonomy, meaningful work, felt competence, task enjoyment and challenging work. These themes formed the basis for the development of items (Victor \& Hoole, in press).

\section{Research method Research participants}

Non-probability convenience sampling was used to collect data from the final sample $(N=639)$. To generalise findings, the sample was made as broad and representative as possible. To ensure that the sample was sufficiently representative and to enhance external validity, participants were required to have at least 1 year of working experience and be proficient in the English language.

A detailed breakdown of the samples demographics is presented (Table 1).

\section{Measuring instruments}

A biographical questionnaire required participants to indicate their age, gender, race, home language and occupational category. The Rewards Desirability Inventory (RDI) was developed to measure preferences towards different types of rewards by asking participants to indicate how important each type is to them. Based on a literature review and the qualitative findings from phase 1 (Victor \& Hoole, 2021), the researcher devised 372 items. After reviewing these items, 100 of the best items (underlying three dimensions, namely, financial rewards, non-financial rewards and intrinsic psychological rewards) were chosen to be retained for expert and layperson evaluation. The questionnaire draft was reduced to 60 items and used to collect data from participants. Following quantitative analyses, the final instrument consisted of 32 items. A 5-point Likert-type scale is used to measure responses in intervals from 1 ('Not at all important') to 5 ('Very Important'). Intervals between the minimum and maximum response categories include a 2 ('Somewhat important'), 3 ('Important') and 4 ('Fairly important') response anchor. Likert-type scales comprising 5 points have been reported to produce higher reliability coefficients than those with a lower number of response categories (Krosnick \& Presser, 2009). Additionally, scales with fewer than five points tend to lack variance (Comrey, 1988).

\section{Research procedure and ethical considerations}

Data were collected using both paper-based and online questionnaires. The researcher initiated contact with companies via email. Company representatives either 
TABLE 1: Frequency distribution of sample participants.

\begin{tabular}{|c|c|c|c|}
\hline Item & Category & Frequency $(n)$ & Percentage (\%) \\
\hline \multirow[t]{2}{*}{ Gender } & Male & 302 & 47.30 \\
\hline & Female & 337 & 52.70 \\
\hline \multirow[t]{6}{*}{ Race } & Black & 392 & 61.30 \\
\hline & Coloured & 73 & 11.40 \\
\hline & Indian & 16 & 2.50 \\
\hline & Asian & 3 & 0.50 \\
\hline & White & 150 & 23.50 \\
\hline & Other & 5 & 0.80 \\
\hline \multirow[t]{9}{*}{ Home language } & English & 175 & 27.40 \\
\hline & Afrikaans & 90 & 14.10 \\
\hline & isiXhosa & 54 & 8.50 \\
\hline & isiZulu & 120 & 18.80 \\
\hline & Sesotho & 47 & 7.40 \\
\hline & SiSwati & 35 & 5.50 \\
\hline & Xitsonga & 15 & 2.30 \\
\hline & Sepedi & 61 & 9.50 \\
\hline & Other & 42 & 6.50 \\
\hline \multirow[t]{10}{*}{ Educational qualification } & Grade 12 or lower & 177 & 27.70 \\
\hline & Diploma or certificate & 140 & 21.90 \\
\hline & $\begin{array}{l}\text { Certified Professional } \\
\text { Qualification }\end{array}$ & 52 & 8.10 \\
\hline & BTech & 17 & 2.70 \\
\hline & Bachelor's degree & 69 & 10.80 \\
\hline & Honours degree & 78 & 12.20 \\
\hline & Master's degree & 71 & 11.10 \\
\hline & Doctoral degree & 21 & 3.30 \\
\hline & Other & 12 & 1.90 \\
\hline & Missing & 2 & 0.30 \\
\hline \multirow[t]{17}{*}{ Industry } & $\begin{array}{l}\text { Banking or Insurance } \\
\text { or Finance }\end{array}$ & 77 & 12.10 \\
\hline & Construction & 62 & 9.70 \\
\hline & Education & 52 & 8.10 \\
\hline & Transportation & 13 & 2.00 \\
\hline & Service & 37 & 5.80 \\
\hline & Healthcare & 52 & 8.10 \\
\hline & Sports & 12 & 1.90 \\
\hline & Beauty & 17 & 2.70 \\
\hline & Legal & 36 & 5.60 \\
\hline & Events or Hospitality & 16 & 2.50 \\
\hline & Mining & 8 & 1.30 \\
\hline & Retail & 61 & 9.50 \\
\hline & Agriculture & 11 & 1.70 \\
\hline & Aviation & 2 & 0.30 \\
\hline & Automotive & 15 & 2.40 \\
\hline & Other & 159 & 24.90 \\
\hline & Missing & 9 & 1.40 \\
\hline \multirow[t]{6}{*}{ Work experience (years) } & 1 to 6 & 209 & 32.70 \\
\hline & 6 to 10 & 135 & 21.10 \\
\hline & 11 to 20 & 127 & 19.90 \\
\hline & $21+$ & 162 & 25.30 \\
\hline & Other & 1 & 0.20 \\
\hline & Missing & 5 & 0.80 \\
\hline
\end{tabular}

forwarded the email with an electronic survey link to participants or requested paper-based questionnaires to be delivered. Paper-based questionnaires were handed back to the company representative within 2 weeks. Electronic questionnaires were completed at the leisure of participants within a month of the email request. The remaining participants were recruited via social media platforms including LinkedIn and Facebook. Electronic links to the survey were open for 2 months and reminder adverts to participate in the study were carried out at weekly intervals.

Approval was granted from the relevant institution to conduct research. Participants were informed of (1) the nature and purpose of the study, (2) option to voluntarily participate and withdraw, (3) an indication that responses will remain confidential and anonymous and (4) contact details of the research team. All data collected were stored electronically via a password protected system.

\section{Statistical analysis}

Data were screened for input errors, unengaged and/or unexpected response cases. Missing cases were replaced using the 'mice' (multivariate imputation by chained equations) package in $\mathrm{R}$ (Version 3.6.2.). An exploratory factor analysis (EFA) and confirmatory factor analysis (CFA) were carried out. Data suitability to verify factorability was explored by scrutinising the Kaiser-MeyerOlkin Measure of Sampling Adequacy (KMO; Kaiser, 1970) as well as Bartlett's test of sphericity for statistical significance and correlation matrix factorability (Bartlett, 1954). Values between 0.50 and 1 for the KMO and significance values of $p=0.005$ or $p=0.001$ for Bartlett's test were used to test assumptions to indicate usefulness. An EFA was used for the purpose of maximising explained covariance and reliability by reducing the number of items, exploring the number of potential dimensions and confirming the factor structure. To replicate the correlation matrix, the researchers made use of Maximum Likelihood (ML). An oblique (direct oblimin) rotation strategy was chosen. General inclusion for item retention included factor loadings between 0.30 and 0.50 , the presence of no crossloadings, factors consisting of at least three items, evidence of reliability (using the Cronbach alpha coefficient; > 0.70; Nunnally \& Bernstein, 1994) and convergence based on theoretical guidance (Carpenter, 2018).

A CFA was used to verify the factor structure using the 'lavaan' package in R. Using a robust ML estimation method, the estimated factor structure was tested. To analyse model fit, goodness-of-fit indices were calculated. The following fit statistics were analysed: Chi-square $\left(\mathrm{X}^{2}\right.$; where the $p$ value should not be statistically significant; Garson, 2005), Degrees of freedom (df), Standardised Root Mean Residual (SRMR; $<0.10$; Kline, 2006), Root Means Square Error of Approximation (RMSEA; between 0.05 and 0.08; Kline, 2006), Tucker Lewis Index (TLI; > 0.90; Kline, 2006), Comparative Fit Index (CFI; > 0.90; Kline, 2006), Akaike's Information Criteria (AIC) and Bayesian Information Criteria (BIC).

Item response theory was used to further test and assess underlying psychometric properties of the RDI using Winsteps (Version 4.4.8). Firstly, the researcher explored functioning of rating scales. The category probability, category frequencies and chi-square fit statistics were evaluated. Fit statistics were acceptable at between 0.50 and 1.5 (Linacre, 2017). 
Andrich thresholds and category measures were evaluated. Secondly, unidimensionality was assessed using principal components analysis on standardised residuals. According to Linacre (2016) upon inspection of the first contrast, eigenvalues $>2$ imply a second dimension. Thirdly, item fit was analysed by screening the item characteristics curve (ICC). Misfit was detected when the ICC diverged considerably from the expected curve (outside the 95\% confidence interval). To confirm whether these items were problematic, the researchers inspected item fit statistics. Item locations, standard errors and fit statistics for each item were assessed. Acceptable logits for item fit were set at between 0.70 and 1.30 (Adams \& Khoo, 1995). Fourthly, summary fit statistics were inspected. The mean of the squared residuals (MNSQ) assessing infit and outfit for persons and items was evaluated. Mean square values $>1$ indicated underfit whereas values $<1$ indicated overfit (Linacre, 2016). Finally, to determine scale reliability for the estimated dimensions for the purpose of proving internal consistency and person and item separation, the following statistics were assessed: Cronbach's alpha coefficient, person and item reliability and person and item separation indices. Cut-off values were set at $>1.50$ for person and item separation indices and $>00.70$ for person and item reliability (Linacre, 2012).

\section{Results}

The KMO test produced an index of 0.95 whilst Bartlett's test of sphericity was significant at $p=0.000$ (Chisq $=11$ 709.64; $d f=1770$ ), indicating that the data were suitable for factor analysis. Guiding theory and research results obtained in the qualitative phase suggested three types of rewards categories. Hence, a three-factor solution was imposed. The solution was run multiple times until simple structure was achieved. The cumulative variance explained produced a value of $47 \%$. The final simple structure matrix with alpha coefficients is outlined (Table 2). It is noted that the three-factor solution provided a good fit from a theoretical and empirical perspective.

With regard to the CFA, although a perfect fit was not obtained $(p<0.000)$, the researcher concluded that the model

TABLE 2: Pattern matrix for the three-factor solution.

\begin{tabular}{|c|c|c|c|c|}
\hline \multirow[t]{2}{*}{ Items and factor labels } & \multicolumn{4}{|c|}{ Factors } \\
\hline & A & 1 & 2 & 3 \\
\hline Non-financial rewards & 0.95 & - & - & - \\
\hline Item 28: Am confident in my abilities to do my job & - & 0.81 & - & - \\
\hline Item 47: Am able to see results for work that I have started and completed & - & 0.76 & - & - \\
\hline Item 44: Feel proud about the work that I produce & - & 0.74 & - & - \\
\hline Item 39: Do work that I am passionate about & - & 0.73 & - & - \\
\hline Item 27: Am kept well informed about important information at work & - & 0.70 & - & - \\
\hline Item 5: Have the skills and abilities to do my work & - & 0.69 & - & - \\
\hline Item 12: Know that I am good at my job & - & 0.69 & - & - \\
\hline Item 37: Do work that gives me a sense of achievement & - & 0.69 & - & - \\
\hline Item 43: Work for a company that encourages good communication & - & 0.67 & - & - \\
\hline Item 32: Fully complete work task from start to finish & - & 0.66 & - & - \\
\hline Item 50: Do work that requires me to put in the extra effort & - & 0.66 & - & - \\
\hline Item 49: Do work that I enjoy & - & 0.65 & - & - \\
\hline Item 54: Feel part of my company's successes & - & 0.65 & - & - \\
\hline Item 24: Do work that I find interesting & - & 0.64 & - & - \\
\hline Item 40: Do work that has a positive impact on other people & - & 0.63 & - & - \\
\hline Item 26: Am a good fit for my company's culture & - & 0.57 & - & - \\
\hline Item 15: Do work that challenges me & - & 0.56 & - & - \\
\hline Item 18: Have a supervisor or manager who trusts me & - & 0.54 & - & - \\
\hline Item 36: Work in an organised (structured) environment & - & 0.53 & - & - \\
\hline Item 22: Will keep my job regardless of my company's economic problems & - & 0.49 & - & - \\
\hline Item 4: Have freedom in choosing how I should go about completing my work tasks & - & 0.46 & - & - \\
\hline Item 19: Am able to complete work tasks according to my liking & & 0.38 & - & - \\
\hline Financial rewards & 0.85 & - & - & - \\
\hline Item 17: Regularly receive a pay cheque & - & - & 0.74 & - \\
\hline Item 41: Get paid on a regular basis & - & - & 0.73 & - \\
\hline Item 60: Receive a salary, wage or hourly rate of pay for the work that I do & - & - & 0.49 & - \\
\hline Benefits and growth opportunities & 0.80 & - & - & - \\
\hline Item 14: Work for a company that pays money towards my medical aid & - & - & - & 0.84 \\
\hline Item 52: Work for a company that pays money towards my pension or retirement fund & - & - & - & 0.62 \\
\hline Item 11: Work for a company that offers training relevant to my needs & - & - & - & 0.45 \\
\hline Item 30: Have opportunities to be promoted & - & - & - & 0.39 \\
\hline
\end{tabular}


produced acceptable fit. An inspection of the items showed that all items produced low standard errors and loaded well onto their respective latent constructs. On assessing the model values collectively, these results suggest that the theoretically driven three-factor solution produced adequate fit, although certain indicators fell slightly beyond the acceptable cut-off values. For a summary of the goodness-offit indices (see Table 3).

With regard to the Rasch analysis, good functioning of ratings was apparent in that each category featured as a unique point in the dataset and no disorder in the category thresholds was detected. The category probability curves were distributed from -7 to 7 logits. Proper ordering of categories was evident and each category measured a unique part of the underlying trait (see Figure 1).

As demonstrated, more than $75 \%$ of responses were captured by Categories 4 and 5 (Table 4 ). With regard to the chi-square fit statistics, the infit MNSQ ranged from 0.88 to 1.66, and the outfit MNSQ ranged from 0.75 to 2.16. Therefore, acceptable fit for each category was mostly observed. It is noted that Category 1 did not fall within the parameters of 0.50 and 1.5 as per Linacre's (2017) recommendations and thus displayed underfit. This category produced an outfit MNSQ of 2.16, which is higher than desired. A plausible explanation for this may be the low frequency count $(3 \%)$ for Category 1. Therefore, the researcher decided not to collapse this

TABLE 3: Goodness-of-fit indices.

\begin{tabular}{lcccccccc}
\hline Model & $\chi^{2}$ & D $\boldsymbol{f}$ & TLI & CFI & RMSEA & SRMR & AIC & BIC \\
\hline Model 1 & 1422.632 & 492 & 0.821 & 0.833 & 0.078 & 0.056 & 25321.615 & 25580.103
\end{tabular}

AIC, Akaike's Information Criteria; BIC, Bayesian Information Criteria; CFI, Comparative Fit Index; Df, Degrees of freedom; RMSEA, Root Means Square Error of Approximation; SRMR, Standardised Root Mean Residual; TLI, Tucker Lewis Index.

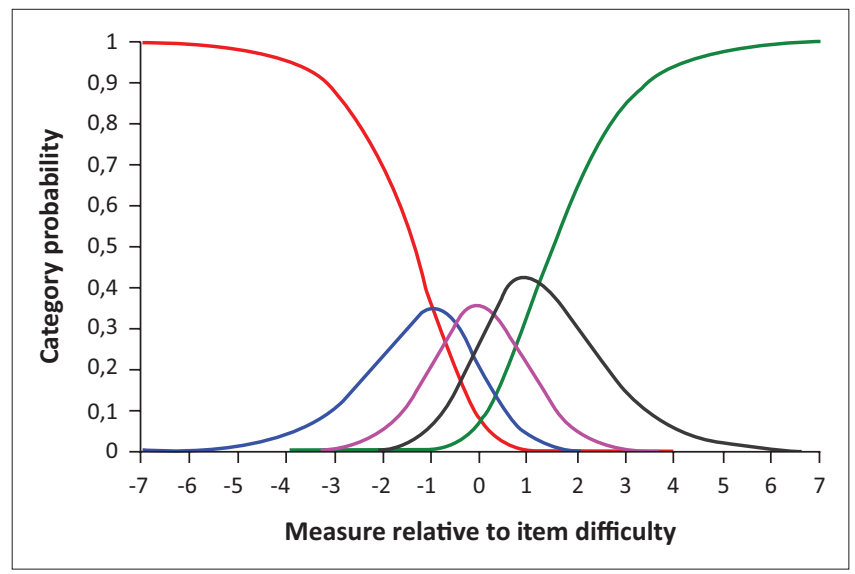

FIGURE 1: Category probability curves for the 5-point rating scale.

\begin{tabular}{|c|c|c|c|c|c|c|}
\hline $\begin{array}{l}\text { Response } \\
\text { category }\end{array}$ & Observed & $\%$ & $\begin{array}{l}\text { Infit } \\
\text { MNSQ }\end{array}$ & Outfit MNSQ & $\begin{array}{l}\text { Andrich } \\
\text { threshold }\end{array}$ & $\begin{array}{l}\text { Category } \\
\text { measure }\end{array}$ \\
\hline 1 & 604 & 3 & 1.66 & 2.16 & NONE & $(-2.38)$ \\
\hline 2 & 1222 & 6 & 0.88 & 1.01 & -0.93 & -1.00 \\
\hline 3 & 3251 & 16 & 0.93 & 1.03 & -0.55 & -0.07 \\
\hline 4 & 6446 & 31 & 0.84 & 0.75 & 0.23 & 0.96 \\
\hline 5 & 9331 & 45 & 0.96 & 0.97 & 1.24 & $(2.56)$ \\
\hline
\end{tabular}

MNSQ, mean of the squared residuals. category. Upon inspection of the Andrich thresholds and category measures, it was evident that categories were properly ordered, despite the misfit for Category 1 . This depicted good evidence of construct validity.

The Wright Map ranged from low (-2 logits) to high (5 logits). The higher a person scored on the latent construct, the more probable it was that the person would select a higher category (i.e. 4 or 5). In addition, item 14 was the most difficult to endorse, whereas item 5 was the easiest.

The average measures for both persons and items (indicated by the letter $M$ on the continuum) are depicted (Figure 2). The mean person ability exceeded the mean item difficulty by approximately 1 logit. This implies that the overall RDI was a fairly easy test for this sample, and that the test did well at measuring those individuals who scored high on reward preferences.

With regard to unidimensionality, eigenvalues produced coefficients of $<2$ upon inspection of the first contrast for all three dimensions (Linacre, 2016). The ICCs showed that the empirical or observed curve for most items matched the expected or theoretical curve and hence, did not deviate substantially by falling beyond the $95 \%$ confidence interval parameters. These items were therefore, considered to perform well and fit the Rasch Model.

With regard to Factor 1, Items 9, 19 and 22 appeared to display some misfit. Specifically, the ICC for these items showed that individuals who scored low on Factor 1 were scoring higher than expected, and vice versa. The summary fit statistics are presented (Table 5). The minor misfit of these items was taken into consideration, and further analysis was approached with caution. For Factor 1, the mean infit and outfit MNSQ for persons were 1.10 (standard deviation $[S D]=0.71)$ and $1.05(S D=0.66)$, respectively. In terms of the items, the mean infit and outfit MNSQ were $1(\mathrm{SD}=0.19)$ and $1.05(\mathrm{SD}=0.27)$, respectively. Item 19 was the hardest item to endorse $(\delta=0.66)$, whilst item 5 was the easiest $(\delta=-0.57)$. The infit MNSQ ranged from 0.74 to 1.52 , and the outfit MNSQ ranged from 0.67 to 1.80 . All items, except for item 22 had acceptable fit. Item 22 showed underfit, with an infit and outfit MNSQ of 1.52 and 1.80, respectively. The statistics confirmed the misfit of item 22 that was previously identified. It should be considered setting this item aside in future administrations.

With regard to Factor 2, item 60 appeared to display misfit. The ICC for this item showed that individuals who scored low on Factor 2 were scoring higher than expected, and vice versa. A plausible explanation for this may be that individuals displayed extreme behaviour towards these items. The minor misfit of this item was taken into consideration, and further analysis was approached with caution. The mean infit and outfit MNSQ for persons were both 0.99 ( $\mathrm{SD}=-0.10)$. In terms of the items, the mean infit and outfit MNSQ were $0.81(\mathrm{SD}=0.13)$ and 0.82 


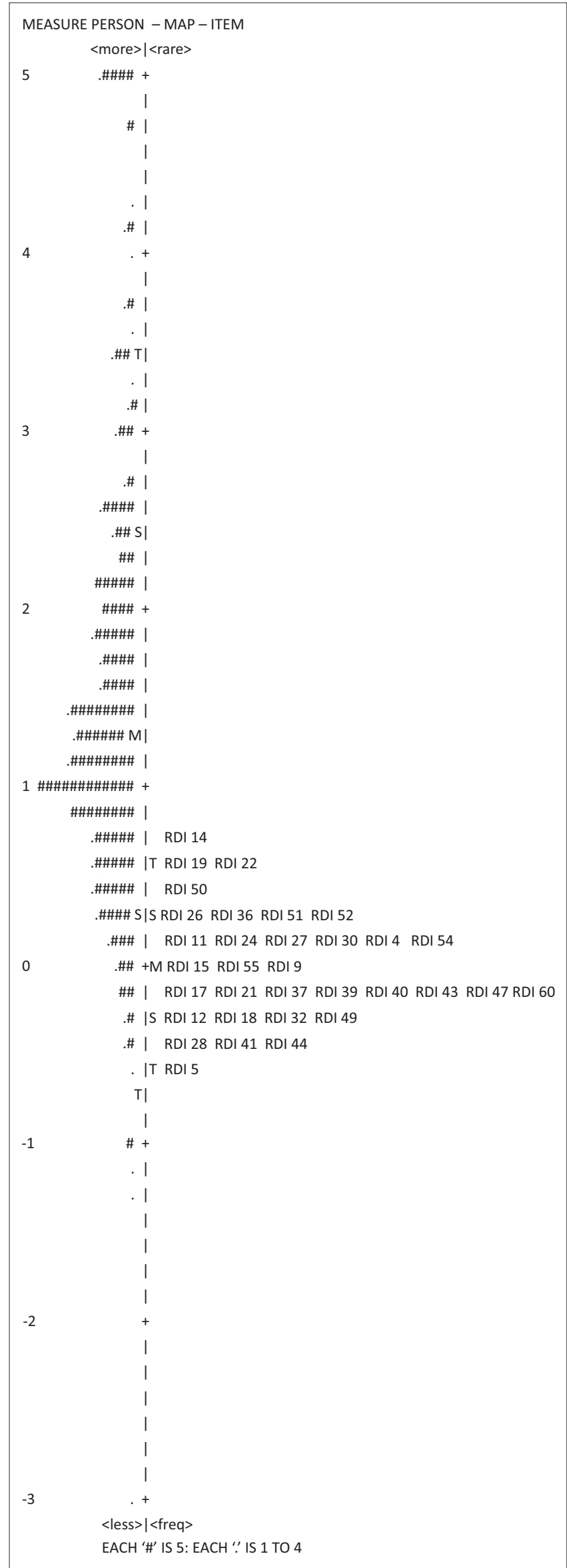

RDI, Rewards Desirability Inventory.

FIGURE 2: Wright Map (Item or person locations).
TABLE 5: Summary item fit statistics.

\begin{tabular}{|c|c|c|c|c|c|c|c|}
\hline Factor & Item & Measure & SE & Infit MNSQ & $t$ & Outfit MNSQ & $t$ \\
\hline \multirow[t]{25}{*}{1} & RDI 19 & 0.66 & 0.05 & 1.39 & 6.12 & 1.49 & 6.87 \\
\hline & RDI 22 & 0.63 & 0.05 & 1.52 & 7.87 & 1.80 & 9.90 \\
\hline & RDI 50 & 0.54 & 0.05 & 1.00 & 0.05 & 1.11 & 1.75 \\
\hline & RDI 26 & 0.39 & 0.05 & 0.98 & -0.25 & 1.04 & 0.68 \\
\hline & RDI 36 & 0.37 & 0.05 & 1.25 & 3.95 & 1.46 & 6.11 \\
\hline & RDI 4 & 0.26 & 0.05 & 1.19 & 3.01 & 1.37 & 4.92 \\
\hline & RDI 24 & 0.16 & 0.05 & 1.16 & 2.52 & 1.29 & 3.86 \\
\hline & RDI 27 & 0.16 & 0.05 & 0.97 & -0.47 & 1.09 & 1.31 \\
\hline & RDI 54 & 0.13 & 0.05 & 0.95 & -0.80 & 1.02 & 0.34 \\
\hline & RDI 9 & 0.07 & 0.05 & 0.95 & -0.81 & 1.14 & 1.87 \\
\hline & RDI 15 & 0.04 & 0.05 & 0.91 & -1.47 & 0.89 & -1.64 \\
\hline & RDI 43 & -0.07 & 0.06 & 0.88 & -2.04 & 0.86 & -2.02 \\
\hline & RDI 40 & -0.10 & 0.06 & 1.11 & 1.78 & 1.17 & 2.17 \\
\hline & RDI 47 & -0.11 & 0.06 & 0.74 & -4.49 & 0.73 & -3.99 \\
\hline & RDI 21 & -0.18 & 0.06 & 0.83 & -2.77 & 0.84 & -2.22 \\
\hline & RDI 37 & -0.18 & 0.06 & 0.77 & -3.85 & 0.71 & -4.18 \\
\hline & RDI 39 & -0.20 & 0.06 & 0.93 & -1.14 & 0.92 & -1.05 \\
\hline & RDI 32 & -0.21 & 0.06 & 1.02 & 0.32 & 0.93 & -0.92 \\
\hline & RDI 49 & -0.22 & 0.06 & 0.85 & -2.43 & 0.90 & -1.32 \\
\hline & RDI 18 & -0.30 & 0.06 & 1.03 & 0.42 & 1.12 & 1.52 \\
\hline & RDI 12 & -0.36 & 0.06 & 0.98 & 0.34 & 1.00 & 0.00 \\
\hline & RDI 28 & -0.40 & 0.06 & 0.83 & -2.81 & 0.75 & -3.32 \\
\hline & RDI 44 & -0.52 & 0.06 & 0.78 & -3.57 & 0.67 & -4.40 \\
\hline & RDI 5 & -0.57 & 0.06 & 0.95 & -0.80 & 0.93 & -0.82 \\
\hline & RDI 51 & 0.46 & 0.06 & 1.01 & 0.23 & 1.02 & 0.29 \\
\hline \multirow[t]{4}{*}{2} & RDI 55 & 0.11 & 0.06 & 0.88 & -1.76 & 0.90 & -1.53 \\
\hline & RDI 17 & -0.05 & 0.06 & 1.17 & 2.29 & 1.14 & 1.86 \\
\hline & RDI 60 & -0.10 & 0.06 & 0.99 & -0.06 & 0.98 & -0.22 \\
\hline & RDI 41 & -0.42 & 0.06 & 0.99 & -0.05 & 0.90 & -1.25 \\
\hline \multirow[t]{4}{*}{3} & RDI 14 & 0.44 & 0.05 & 0.87 & -0.28 & 0.84 & -2.75 \\
\hline & RDI 52 & -0.01 & 0.05 & 0.98 & -0.30 & 0.93 & -1.02 \\
\hline & RDI 11 & -0.21 & 0.06 & 0.97 & -0.43 & 1.02 & 0.26 \\
\hline & RDI 30 & -0.22 & 0.06 & 1.13 & 1.95 & 1.10 & 1.41 \\
\hline
\end{tabular}

$\mathrm{RDI}$, Rewards Desirability Inventory; MNSQ, mean of the squared residuals.

$(\mathrm{SD}=0.13)$, respectively. Item 51 was the hardest item to endorse $(\delta=0.46)$, whilst item 41 was the easiest $(\delta=-0.42)$. In terms of item fit, the infit MNSQ ranged from 0.88 to 1.17 , and the outfit MNSQ ranged from 0.90 to 1.14. These fit statistics did not evidence misfit. All items were, therefore, retained.

With regard to Factor 3, inspection of the ICCs evidenced that no items appeared to display misfit. The mean infit and outfit MNSQ for persons were $0.96(\mathrm{SD}=-0.2)$ and 0.97 (SD $=-0.10)$. In terms of items, the mean infit and outfit MNSQ were $0.99(\mathrm{SD}=-0.30)$ and $0.97(\mathrm{SD}=-0.50)$, respectively. Item 14 was the hardest item to endorse $(\delta=0.44)$, whilst item 30 was the easiest $(\delta=-0.22)$. In terms of item fit, the infit MNSQ ranged from 0.87 to 1.13 , and the outfit MNSQ ranged from 0.84 to 1.10 . As per the desired range, these fit statistics did not evidence misfit. All items were, therefore, retained.

For Factor 1, the person reliability was 0.87 , with a person separation index of 2.59 . The item reliability was 0.97 , with an item separation index of 5.83. Cronbach's alpha was 0.95 . For Factor 2, the person reliability was 0.62 , with a person separation index of 1.27 . The item reliability was 0.95 , with an item separation index of 4.61. Cronbach's alpha was 0.86 . For Factor 3, the person reliability was 0.64 , with a person 
separation index of 1.33 . The item reliability was 0.96 , with an item separation index of 4.76. Cronbach's alpha was 0.81 .

\section{Discussion Outline of the results}

The aim of this study was to develop and validate the RDI to assess the extent to which individuals show preferences towards different types of rewards. The final measure consisted of 32 items. The dimensions were labelled as non-financial rewards, financial rewards and benefit and growth opportunities. These findings are partially consistent with the results from Khan, Shahid, Nawab and Wali (2013) which reported that nonfinancial rewards and financial rewards underlie reward preferences. The research results demonstrated reliability of the instrument, with satisfactory Cronbach alpha coefficients for all three constructs. Thus, the results signify the potential value of the RDI as a useful instrument for measuring reward preferences from a financial, non-financial and benefit and growth opportunity perspective. The findings of the CFA further support the application of a three-dimensional model. The investigation of the fit indices revealed that the dimensional structure of the RDI was acceptable.

This scale was developed in response to a need for a reward desirability scale that takes into account, not only financial rewards and non-financial but intrinsic psychological rewards as well. Although the hypothesised model was only partially supported, it is important to note that the nonfinancial rewards category consisted of both non-financial and intrinsic psychological rewards. The financial rewards category conformed as hypothesised whilst the benefits and growth opportunity category was unexpected. As such, it is important to review each dimension in relation to prior research. The first dimension was labelled non-financial rewards and consisted of both non-financial and intrinsic psychological rewards. A potential explanation of why these items may have loaded onto the same dimension is because both types of rewards were defined as intangible in nature (e.g. Jacobs et al., 2014; Joshi, 2016). Therefore, both concepts share similar attributes. The second dimension was labelled as financial rewards and consisted of items which pertain to pay as derived in prior literature (Hoole \& Hotz, 2016). Pay has been recognised as a dimension measuring financial reward preferences in the workplace (Snelgar et al., 2013). The third dimension was labelled as benefit and growth opportunities and consisted of employer contributions as well as opportunities for training and advancement. This result was unexpected as benefits were hypothesised as a financial reward whereas opportunities for training and promotion were deemed non-financial. A possible explanation for this is that these rewards cannot be classified as either financial or non-financial in nature. For example, employees may perceive benefits as rewards which they receive as being nonfinancial in nature. Benefits contribute towards satisfying their personal needs. Similarly, training and advancement opportunities in the workplace also support and satisfy one's personal needs. Whilst training enhances skillsets, knowledge and competencies, advancement enhances one's personal growth and development. Both benefits and training and advancement are likely to cost the employer financially. Given this, employees are aware that benefits, training opportunities and advancement within an organisation are at the expense of the employer whilst directly benefiting and satisfying an employee's individual needs.

Through the application of a Rasch analysis, the researcher was able to further investigate the psychometric properties of the instrument. In accordance with the fit statistics, measures and thresholds for the categories, it was evident that the response categories performed adequately in accordance with Rasch Model expectations. The majority of the sample endorsed Categories 4 ('very important to me') and 5 ('extremely important to me') when specifying their preferences towards rewards. The item-person map confirmed these findings.

A potential reason as to why the majority of the sample felt that rewards were important to them is best explained by Herzberg's two-factor theory (Herzberg et al., 1959). Based on this theory, humans at work seek to prevent job dissatisfaction and enhance their motivation. In line with the dimensions of the RDI, this can be achieved by offering financial rewards (i.e. salary), non-financial rewards (i.e. interpersonal relations, recognition, responsibility and work itself) and benefit and growth opportunities (i.e. possibility of growth and advancement) to employees in the workplace. Therefore, humans are likely more attracted to workplace rewards which stimulate satisfaction and prevent dissatisfaction, potentially explaining why they place importance on different types.

Findings of the Rasch analysis confirmed a three-factor structure (as supported by the factor analyses), with each subscale displaying unidimensionality. In accordance with the individual items for Factor 1 (non-financial rewards), Item 22 ('Will keep my job regardless of my company's economic problems') displayed some misfit in the form of underfit. It was also the second hardest item to endorse. Bond and Fox (2007) suggested that misfit of items may be because of content and wording issues. Conceptually, the item wording does appear to be problematic. The words 'regardless' and 'economic problems' are complex and ambiguous in nature. Regardless of this, this item appears problematic and should be precluded from future administrations.

In line with the reliability of the factors, internal consistency was acceptable for all dimensions. In addition, all factors evidenced adequate item reliability and item separation index coefficients, indicating that the sample size was adequate. For Factors 2 and 3, the person reliability and person separation coefficients were below the desired values as recommended by Linacre (2012). These factors may require the inclusion of additional items (Linacre, 2012). Based on the overall results, one can confirm that the new instrument has satisfactory psychometric properties. 


\section{Practical implications}

This article offers researchers and managers a tool to explore reward preferences more holistically and intricately. Specifically, those who are interested in exploring what employees ultimately value from their job can use this tool to detect which specific types of rewards employees seek from their working engagements. Moreover, this study offers a credible tool for data collection and analyses for the broader purpose of making sound reward-related decisions. This may be useful in business contexts pertaining to career development, attraction and retention, recruitment and selection and reward and remuneration.

It is particularly noted that this tool can be used to enhance talent management strategies in that managers will have improved insight into how rewards can be better implemented and distributed to suit individual preferences and needs. This article provides managers with awareness that the provision of intrinsic psychological rewards is as equally important as extrinsic reward offerings. Therefore, this study provides insight into why job tasks can be better structured to elicit positive emotional experiences felt by employees when engaging in their actual work. As previously alluded to, the combination of extrinsic and intrinsic psychological rewards can assist employees in delivering their finest performance and satisfying their needs. Having said this, managers could use this tool to identify suitable levers for non-financial and intrinsic psychological rewards, for example, identifying gaps in training and development or identifying how jobs could be redesigned to enhance employee work motivation and job satisfaction.

\section{Limitations and recommendations}

Firstly, participants were required to complete a self-report measure. Participants may have answered inaccurately as a result of social desirability bias. An alternative explanation for giving inaccurate answers may be attributed to participants misinterpreting item statements (item ambiguity or difficulty). It must be noted that this study serves as the first version of the RDI, thereby allowing for further development and refinement in future studies. Secondly, the sample of this study consisted solely of working South Africans. Generalising these findings to other countries should be carried out with caution. For future research purposes, it is recommended that the research method and sample be extended to international contexts. Thirdly, the three-factor solution was selected as suggested by theory. However, it was evident that the subscales partially supported the hypothesised dimensions. It is, therefore, recommended that future studies replicate the research results to determine whether three-factors do indeed underlie reward preferences.

\section{Conclusion}

This study reinforces the idea that there are multiple rewards which employees seek and value from their work. Therefore, total reward packages should be updated to focus more on non-financial rewards and particularly, on the inclusion of intrinsic psychological rewards. This study formed part of the second phase of a broader exploratory sequential mixed methods study to develop and validate the RDI. Underlying total rewards, and therefore, reward preferences are three dimensions: non-financial rewards, financial rewards and benefit and growth opportunities. After completing and interpreting scores from the instrument, managers can develop a better understanding of what employees seek from their work. In turn, managers can devise remuneration packages to suit individual employees' needs so that employees are more motivated and satisfied in their jobs. Although the instrument should be subject to further scrutiny and refinement, the preliminary results of this instrument reveal satisfactory psychometric properties in the South African context.

\section{Acknowledgements Competing interests}

The authors have declared that no competing interests exist.

\section{Author's contributions}

The study was conducted by J.A.V. as part of her PhD in Industrial Psychology at the University of Johannesburg in 2020. C.H. was J.A.V.'s supervisor and edited the work for publication. Both authors contributed significantly to the conceptualisation and review of the study.

\section{Ethical considerations}

Ethical clearance was obtained from the research committee of the primary research institution. IPPM-2017-162 (D).

\section{Funding information}

This research received no specific grant from any funding agency in the public, commercial or not-for-profit sectors.

\section{Data availability}

The data that support the findings of this study are available from the corresponding author (C.H.) upon reasonable request.

\section{Disclaimer}

The views and opinions expressed in the article are those of the authors and do not represent the views of any affiliated institution.

\section{References}

Acheampong, N.A.A. (2021). Reward preferences of the youngest generation Attracting, recruiting, and retaining generation $\mathrm{Z}$ into public sector organizations. Compensation \& Benefits Review, 53(2), 75-97. https://doi.org/10.1177/088636 8720954803

Achor, S., Reece, A., Kellerman, G.R., \& Robichaux, A. (2018). 9 out of 10 people are willing to earn less money to do more-meaningful work. Retrieved from https:// $\mathrm{hbr}$.org/2018/11/9-out-of-10-people-are-willing-to-earn-less-money-to-domore-meaningful-work

Adams, R.J., \& Khoo, S.T. (1995). Quest: Interactive item analysis. Melbourne: ACER. 
Adinew, T. (2020). Examining employees' reward preference and its association with motivation to work: A case of ethio-Telecom (Adama Branch). European Journal of Business and Management, 12(13), 10-28. https://doi.org/10.7176/EJBM/ of Business

Alhmoud, A., \& Rjoub, H. (2019). Total rewards and employee retention in a middle Eastern context. SAGE Open, 9(2), 215824401984011. https://doi.org/10.1177/ 2158244019840118

Ali, M.A.S., Said, A.N., Yunus, M.N., Kader, A.F.S., Latif, A.S.D., \& Munap, R. (2014) Hackman and Oldham's job characteristics model to job satisfaction. Procedia Social and Behavioral Sciences, 129, 46-52. https://doi.org/10.1016/j.sbspro. 2014.03.646

Armstrong, M. (2010). Armstrong's handbook of reward management practice: Improving performance through reward. London: Kogan Page Publishers.

Avey, J.B., Avolio, B.J., Crossley, C.D., \& Luthans, F. (2009). Psychological ownership: Theoretical extensions, measurement and relation to work outcomes. Journal of Organizational Behavior: The International Journal of Industrial, Occupationa and Organizational Psychology and Behavior, 30(2), 173-191. https://doi.org/ $10.1002 /$ job.583

Bartlett, M.S. (1954). Significance test for sphericity of a normal n-variate distribution. Journal of the Royal Statistical Society, 16(2), 296-298. https://doi.org/10.1111/ j.2517-6161.1954.tb00174.x

Close, D., \& Martins, N. (2015). Generational motivation and preference for reward and recognition. Journal of Governance and Regulation, 4(3), 258-270. https:// doi.org/10.22495/jgr_v4_i3_c2_p8

Bond, T.G., \& Fox, C.M. (2007). Applying the Rasch model: Fundamental measurement in the human sciences (2nd ed.). Mahwah, NJ: Lawrence Erlbaum Associates.

Brown, D. (2014). The future of reward management: From total reward strategies to smart rewards. Compensation \& Benefits Review, 46(3), 147-151. https://doi. org $/ 10.1177 / 0886368714549303$

Bussin, M., Mohamed-Padayachee, K., \& Serumaga-Zake, P. (2019). A total rewards framework for the attraction of Generation Y employees born 1981-2000 in South Africa. SA Journal of Human Resource Management, 17, a1066. https://doi. org/10.4102/sajhrm.v17i0.1066

Bussin, M., Nicholls, M., \& Nienaber, R. (2016). The relationship between occupational culture dimensions and reward preferences: A structural equation modelling approach. SA Journal of Human Resource Management, 14(1), a737. https://doi. org/10.4102/sajhrm.v14i1.737

Bussin, M., \& Thabethe, N.N. (2018). Reward preferences in South Africa's media industry. SA Journal of Human Resource Management, 16, a1010. https://doi. org/10.4102/sajhrm.v16i0.1010

Bussin, M., \& Van Rooy, D.J. (2014). Total rewards strategy for a multi-generational workforce in a financial institution. SA Journal of Human Resource Management 12(1), 1-11. https://doi.org/10.4102/sajhrm.v12i1.606

Carpenter, S. (2018). Ten steps in scale development and reporting: A guide for researchers. Communication Methods and Measures, 12(1), 25-44. https://doi. org/10.1080/19312458.2017.1396583

Chiang, F.F., \& Birtch, T.A. (2005). A taxonomy of reward preference: Examining country differences. Journal of International Management, 11(3), 357-375. https://doi.org/10.1016/j.intman.2005.06.004

Comrey, A.L. (1988). Factor-analytic methods of scale development in personality and clinical psychology. Journal of Consulting and Clinical Psychology, 56(5), 754-761. https://doi.org/10.1037/0022-006X.56.5.754

Crane, M.E. (2012). The effects of task autonomy and task interest on goal-setting behavior and task performance [Doctoral dissertation, Cleveland State University]. ETD Archive. Retrieved from https://engagedscholarship.csuohio. edu/etdarchive/476

Dolan, P., \& Metcalfe, R. (2012). Measuring subjective wellbeing: Recommendations on measures for use by national governments. Journal of social policy, 41(2), 409-427. https://doi.org/10.1017/S0047279411000833

Fobian, D., \& Maloa, F. (2020). Exploration of the reward preferences of generational groups in a fast-moving consumer goods organisation. SA Journal of Huma Resource Management, 18, a1244. https://doi.org/10.4102/sajhrm.v18i0.1244

French, P.E., \& Emerson, M.C. (2014). Assessing the variations in reward preference for local government employees in terms of position, public service motivation, and public sector motivation. Public Performance \& Management Review, 37(4), 552-576. https://doi.org/10.2753/PMR1530-9576370402

García, I.R., Ramón, S.D.C., \& Herrera, A.F. (2019). The role of work motivation based on values in employee's retention in the 21st century. Management Studies, $7(2)$, 149-156. https://doi.org/10.17265/2328-2185/2019.02.007

Garson, G.D. (2005). Statsnotes: An online textbook. Retrieved from http://www. statisticssolutions.com/Validity.htm

Hackman, J.R., \& Oldham, G.R. (1976). Motivation through the Design of Work Organizational Behavior and Human Performance, 16(2), 250-279. https://doi. org/10.1016/0030-5073(76)90016-7

Herzberg, F., Mausner, B., \& Snyderman, B. (1959). The motivation to work (2nd ed.). John Wiley.

Herzberg, F. (1966). Work and the nature of man. World Publishing.

Hoole, C., \& Hotz, G. (2016). The impact of a total reward system of work engagement. SA Journal of Industrial Psychology, 42(1), 1-14. https://doi.org/10.4102/sajip. v42i1.1317

Horváthová, P., Davidová, M., \& Bendová, M. (2012). Contingent pay and experience with its use by organizations of the Czech Republic Operating in the Field of Environmental Protection. International Journal of Economics and Management Engineering, 6(4), 522-526.
Jacobs, S., Renard, M., \& Snelgar, R.J. (2014). Intrinsic rewards and work engagement in the South African retail industry. SA Journal of Industrial Psychology, 40(2), 1-13. https://doi.org/10.4102/sajip.v40i2.119.

Jiang, Z., Xiao, Q., Qi, H., \& Xiao, L. (2009). Total reward strategy: A human resources management strategy going with the trend of the times. International Journal of Business and Management, 4(11), 177-183. https://doi.org/10.5539/ijbm v4n11p177

Joshi, P. (2016). Relational rewards: Creating a fulfilling workplace environment. International Journal of Engineering and Management Research (IJEMR), 6(4), 1-5.

Kaiser, H. F. (1970). A second generation little jiffy. Psychometrika, 35(4), 401-415. https://doi.org/10.1007/BF02291817

Khan, I., Shahid, M., Nawab, S., \& Wali, S. S. (2013). Influence of intrinsic and extrinsic rewards on employee performance: The banking sector of Pakistan. Academic Research International, 4(1), 282.

Kline, R.B. (2006). Formative measurement and feedback loops. In G.R. Hancock \& R.O. Mueller (Eds.), Structural equation modeling: A second course (pp. 43-68) Greenwich, CT: Information Age Publishing.

Koskey, A.K., \& Sakataka, W. (2015). Effect of reward on employee engagement and commitment at Rift Valley Bottlers Company. International Academic Journal of Human Resource and Business Administration, 1(5), 36-54.

Kshirsagar, M., \& Waghale, V.Y. (2014). Impact of financial and non-financial rewards on employee motivation. International Research Journal of Management and Commerce, 1(6), 61-74.

Krosnick, J.A., Presser S. (2009). Question and questionnaire design. In P.V. Marsden \& J.D. Wright (Eds.), Handbook of survey research (pp. 263-313). Bingley: Emerald.

Linacre, J.M. (2012). Winsteps (Version 3.74). Retrieved from http://www.winsteps. com/index.html

Linacre, J.M. (2016). A user's guide to WINSTEPS MINISTEP Rasch model computer programs: Program manual 3.92.0. Retrieved from www.winsteps.com

Linacre, J.M. (2017). Winsteps ${ }^{\circledR}$ Rasch measurement computer program. Beaverton, OR: Winsteps.com

Michaelson, C. (2019). A normative meaning of meaningful work. Journal of Business Ethics, 170, 413-428. https://doi.org/10.1007/s10551-019-04389-0

Neves, D.R., Nascimento, R.P., Felix, Jr, M.S., Silva, F.A.D., \& Andrade, R.O.B.D. (2018). Meaning and significance of work: A review of articles published in journals associated with the Scientific Periodicals Electronic Library. Cadernos EBAPE. BR 16(2), 318-330. https://doi.org/10.1590/1679-395159388

Nguyen, A., Taylor, J., \& Bradley, S., (2003). Relative pay and job satisfaction. Some new evidence (MPRA Paper No 1382). Computer Technology and the Job of the First-line Supervisor New Technology. Work Employment, 2(1), 47-59. Retrieved from https://mpra.ub.uni-muenchen.de/1382/1/MPRA_paper 1382.pdf

Nicholls, M.L. (2012). The relationship between occupational culture, occupational groups and reward preferences [Doctoral thesis, University of Johannesburg] Retrieved from http://hdl.handle.net/10210/8356

Nienaber, R., Bussin, M.H.R., \& Henn, C. (2011). The relationship between personality types and reward preferences. Acta Commercii, 11(2), 56-79. https://doi. org/10.4102/ac.v11i2.153

Noor, S.N.A.M., \& Zainordin, N. (2018). The impact of rewards as motivation on job satisfaction in a quantity surveying consult firm. International Journal of Modern Trends in Social Sciences, 1(4), 1-14.

Nunnally, J.C., \& Bernstein, I.H. (1994). Psychometric theory (3rd ed.). New York, NY: McGraw-Hill.

Obicci, P.A. (2015). Influence of extrinsic and intrinsic rewards on employee engagement: Empirical study in public sector of Uganda. Management Studies and Economic Systems, 54(2518), 1-12. https://doi.org/10.12816/0018083

Overell, S. (2009). The meaning of work [Review for Beyond Current Horizons Programme]. Futurelab. Retrieved from www.beyondcurrenthorizons.org.uk/ evidence/work-and-employment

Ozsoy, E. (2019). An empirical test of Herzberg's two-factor motivation theory. Marketing and Management of Innovations, 1, 11-20. http://doi.org/10.21272/ mmi.2019.1-01

Peng, C. (2018). A literature review of job crafting and its related researches. Journa of Human Resource and Sustainability Studies, 6(1), 1-7. https://doi.org/10.4236/ jhrss.2018.61022

Perry, J.L., \& Porter, L.W. (1982). Factors affecting the context for motivation in public organizations. Academy of Management Review, 7(1), 89-98. https://doi. org/10.5465/amr.1982.4285475

Pink, D.H. (2009). Drive: The surprising truth about what motivates us. New York, NY: Riverhead Books.

Preenen, P., Van Vianen, A., \& De Pater, I. (2014). Challenging tasks: The role of employees' and supervisors' goal orientations. European Journal of Work and Organizational Psychology, 23(1), 48-61. https://doi.org/10.1080/1359432X. 2012.702420

Pregnolato, M., Bussin, M.H., \& Schlechter, A.F. (2017). Total rewards that retain: A study of demographic preferences. SA Journal of Human Resource Management, 15(1), 1-10. https://doi.org/10.4102/sajhrm.v15i0.804

Renard, M., \& Snelgar, R.J. (2016). How can work be designed to be intrinsically rewarding? Qualitative insights from South African non-profit employees. $S A$ Journal of Industrial Psychology, 42(1), 1-12. https://doi.org/10.4102/sajip 
Riaz, H., Akhtar, C.S., \& Aslam, R. (2018). Total rewards and employee performance: Investigating the mediating role of employee motivation in telecom sector.
Pakistan Administrative Review, 2(3), 342-356. Retrieved from https:// Pakistan Administrative Review, 2(3), 342-356.
nbnresolving.org/urn:nbn:de:0168-ssoar-60666-3

Rigby, C.S., \& Ryan, R.M. (2018). Self-determination theory in human resource development: New directions and practical considerations. Advances in Developing Human Resources, 20(2), 133-147. https://doi.org/10.1177/1523422318756954

Ryan, R.M., \& Deci, E.L. (2000). Intrinsic and extrinsic motivations: Classic definitions and new directions. Contemporary educational psychology, 25(1), 54-67. https:// doi.org/10.1006/ceps.1999.1020

Scherer, K.R. (2005). What are emotions? And how can they be measured? Socia Science Information, 44(4), 695-729. https://doi.org/10.1177/0539018405058216

Sels, L., De Winne, S., Delmotte, J., Maes, J., Faems, D., \& Forrier, A. (2006). Linking HRM and small business performance: An examination of the impact of HRM intensity on the productivity and financial performance of small businesses. Small Busines Economics, 26(1), 83-101. Retrieved from https://www.jstor.org/stable/40229455

Snelgar, R.J., Renard, M., \& Venter, D. (2013). An empirical study of the reward preferences of South African employees. SA Journal of Human Resource Management, 11(1), a351. https://doi.org/10.4102/sajhrm.v11i1.351
Ushie, E.M., Agba, A.M.O., \& Okorie, C. (2015). Work environment and employees' commitment in Agro-Based industries in Cross River State, Nigeria. Global Journa of Human-Social Science Research, 15(6), 9-15.

Victor, J., \& Hoole, C. (2017). The influence of organisational rewards on workplace trust and work engagement. SA Journal of Human Resource Management, 15(1), 1-14. https://doi.org/10.4102/sajhrm.v15i0.853

Victor, J.A., \& Hoole, C. (2021). Rejuvenating the rewards typology: Qualitative insights into reward preferences. SA Journal of Industrial Psychology/SA Tydskrif vir Bedryfsielkunde, 47(0), a1880. https://doi.org/10.4102/sajip.v47i0.1880

Williams, G.C., Niemiec, C.P., Patrick, H., Ryan, R.M., \& Deci, E.L. (2009). The importance of supporting autonomy and perceived competence in facilitating long-term tobacco abstinence. Annals of Behavioral Medicine, 37(3), 315-324. https://doi.org/10.1007/s12160-009-9090-y

WorldatWork. (2007). The WorldatWork handbook of compensation, benefits and total rewards: A comprehensive guide for HR professionals. Hoboken, NJ: John Wiley and Sons.

WorldatWork. (2010). WorldatWork introduces revised total rewards model. Retrieved from https://www.worldatwork.org/docs/worldatworkpressreleases/2015/ worldatwork-introduces-revised-total-rewards-model.html 